Kathya Araujo ${ }^{1}$

\title{
La tesis de la individualización en las sociologías alemana y chilena: una lectura crítica ${ }^{2}$
}

Este artículo discute los modos en que el tradicional enfoque de la individuación ha sido prolongado en las últimas décadas desde la tesis de la individualización en dos tradiciones intelectuales distintas: la alemana y la chilena. Es esta tesis la que centralmente ha marcado los debates sobre procesos de individuación en el caso alemán, y la que se ha revelado, en este campo, como una de las más influyentes en las ciencias sociales en el caso chileno.

Procederemos en tres etapas. Primero, se presentará la manera en que la tesis de la individualización ha sido desarrollada en Alemania, en particular en los trabajos de Ulrich Beck, y algunas de las críticas que se le han dirigido. En segundo lugar, se desarrollará cómo esta tesis ha sido recibida y retomada en Chile, centrándose, en especial, en algunas de las principales dificultades y riesgos de esta recepción. Por último, argumentaremos que los límites observables en la tesis de la individualización, invitan, no a abandonar, sino a renovar en América Latina los estudios de la individuación, pero sobre nuevas bases.

Una aclaración inicial parece indispensable. El uso terminológico en este campo que toma como foco los procesos de producción del individuo tiende a generar una cierta oscuridad. La confusión es aumentada porque los términos (individuo, individuación, individualización, individualismo) así como los sentidos de los que se cargan están fuertemente influidos por los rasgos de las tradiciones científicas nacionales o regionales (Martuccelli/Singly 2009; Kalupner 2003). Lo anterior produce un efecto de naturalización del uso terminológico en cada área geográfica de discusión, la que abulta la posibilidad de malentendi-

${ }^{1}$ Doctora en Estudios Americanos. Profesora de la Universidad Academia de Humanismo Cristiano.

2 Mis agradecimientos a la Fundación Alexander von Humboldt por su apoyo en la estadía de investigación de la que este texto es tributario y a los y las colegas del Instituto Latinoamericano de la Universidad Libre de Berlín, y muy en particular a Sèrgio Costa, por su invaluable ayuda y los fructíferos diálogos y encuentros. Parte de las reflexiones aquí incluidas se desarrollaron en el marco del Proyecto Fondecyt, 1085006 "Procesos de individuación y de configuración de sujeto en la sociedad chilena actual", apoyado por la Comisión Nacional de Ciencia y Tecnología de Chile (CONICYT). 
dos. Si bien no es posible hacer una discusión a fondo de estos conceptos, por necesidades de claridad del desarrollo expositivo una distinción se impone entre las dos nociones que aquí movilizamos. Por un lado, y en acuerdo con la manera como la sociología clásica abordó este tema, se entiende por individuación en este artículo la pregunta por los grandes condicionamientos estructurales que producen modalidades históricas distintas de individuo en las diversas sociedades. El enfoque de la individuación propone, así, que para la comprensión de las sociedades una vía privilegiada es el estudio de las formas en que los individuos se producen en sociedades históricamente definidas. Por el otro lado, cuestión que será desarrollada en detalle más adelante, se entiende por individualización una de las lecturas posibles y actualmente vigentes del proceso contemporáneo de individuación. Un abordaje que, privilegiando una perspectiva sobre todo histórica, y por lo general a través de modos ensayísticos, ha puesto el acento en las fuentes institucionales propias a la segunda modernidad o la modernidad tardía (Beck/Beck-Gernsheim 2003; Giddens 2003).

\section{La tesis de la individualización en Alemania}

En el caso de la discusión especializada alemana el término hegemónico en este debate es el de Individualisierung, el que se usa para nombrar un campo que incluye los desarrollos hechos desde diferentes teorías actuales (desde el individualismo metodológico hasta los teóricos de la segunda modernidad o modernidad reflexiva, pasando por enfoques de tipo sistémicos). Un término que en su amplitud incluso comprende bajo esta denominación discusiones históricamente precedentes (en autores clásicos como Durkheim, Weber, Elias o Simmel). Esta amplitud de los usos del término aporta a que en esta tradición aparezca permanentemente una oscilación entre, por un lado, Individualisierung como proceso histórico y, por el otro, propuestas teóricas que plantean modelos para la comprensión de la sociedad a partir de la producción de los individuos (o sea, y en la distinción que hemos introducido más arriba-individuación-). Sin embargo, y a pesar de esta pluralidad semántica, no es abusivo afirmar que, incluso en Alemania, cuando en la discusión se retoma el término de Individualisierung, por diferentes razones -una de ellas no menor, el éxito editorial- la asociación más inmediata del término se suele hacer con los trabajos de Ulrich Beck y su noción de Individualización. Dada su influencia central en los debates de la sociología chilena, será su obra la que será privilegiada en lo que sigue. ${ }^{3}$

${ }^{3}$ En efecto, en el caso del debate especializado chileno, algo que con mucha certeza se puede extender a otros países de la región, la noción de individualización, que ha tenido una 
La noción de individualización tiene dos acepciones. La primera, de uso corriente y de índole estrictamente descriptiva y empírica, designa el proceso de diferenciación creciente de las trayectorias personales. La segunda acepción, de carácter más analítico, asocia el proceso de individualización con el advenimiento de una nueva etapa de la modernidad, y se interesa sobre todo, dentro de esta visión general, por la aparición de un nuevo tipo de individualismo institucional. Es esta segunda acepción del término la que retendrá nuestra atención aun cuando, y es importante subrayarlo, la confusión entre ambos niveles es una constante en estos trabajos.

Es, sin duda, Ulrich Beck el autor a quien se debe la introducción de la tesis de la individualización en el sentido antes mencionado, la que desarrollará, en varias publicaciones, en colaboración con Elisabeth Beck-Gernsheim. Se ha sostenido con insistencia que su difusión está vinculada con el éxito editorial del libro Risikogesellschaft, publicado en 1986, el mismo año que ocurriera el desastre ecológico de Chernobyl (Volkmann 2007; Schroer 2000), desastre que funcionará como una especie de confirmación empírica de la lectura de la sociedad contemporánea que hace el autor. Ese libro contiene ya un capítulo sobre la individualización, como proceso característico de la realidad que estamos enfrentando, pero es su artículo "Jenseits von Stand und Klasse" (Beck 1984), publicado pocos años antes, el que suele ser referido como punto de anclaje inicial para la discusión de esta tesis.

La tesis de la Individualisierung de Beck tiene cuatro grandes características. En primer lugar, propone un diagnóstico de época, que el autor irá progresivamente elaborando teóricamente (Schroer 2000: 408). En segundo lugar, la tesis subraya los cambios observables a nivel de las instituciones como entrada privilegiada para dar cuenta de los procesos actuales de individualización. En tercer lugar, la tesis opta, por lo general de manera solamente implícita, por un modelo particular y normativo de actor -el sujeto reflexivo-. En cuarto y último lugar, y aunque el punto sea más polémico, la tesis posee un potencial crítico - la individualización aparece como una experiencia ambivalente, a la vez luminosa y sombría. Veamos cada uno de estos aspectos.

\section{Un diagnóstico de época}

La tesis de la individualización en Alemania se nutre, por un lado, de la evidencia de la incertidumbre y de la conciencia creciente de la amenazante pre-

significativa difusión en los estudios en ciencias sociales, está fuertemente atada a los aportes de los teóricos de la llamada modernidad reflexiva (Beck, Giddens, Lash) a lo cual podría añadirse la influencia de la obra de Bauman. Es decir a una, y por lo general, solo a una de las varias tesis contemporáneas que discuten los procesos de producción de los individuos. 
sencia de riesgos globales. Es, por otro lado, también producto de lo que aporta a una reflexión sociológica la aparición de una nueva generación que, lejos de aquella de la posguerra que produjo el llamado "milagro alemán", comienza a poner en evidencia nuevas prioridades, patrones de enjuiciamiento, anhelos de realización personal. Es la aparición de una generación, para hacer una paráfrasis, que, por ejemplo, deja de preocuparse, como lo hicieron sus padres, porque el par de zapatos que va a comprar sea lo suficientemente bueno y práctico como para que dure muchos inviernos y sea utilizable en la mayor cantidad de situaciones. Una generación que, por el contrario, empieza a orientar su consumo en función de las tendencias de la moda y del estilo personal.

Para Beck, entonces, el proceso de individualización está directamente ligado a la transformación de factores estructurales que se expresan en la mejora de las condiciones de vida en Alemania desde los años cincuenta y sesenta, los que significaron mayores ingresos, más tiempo y recursos materiales a disposición ("efecto ascensor" [Beck 2006:130], como lo ha llamado, pues no se tradujo necesariamente en una disminución de las desigualdades).

Sin embargo, esto no es sino un primer punto. Para Beck la individualización debe ser entendida, de manera más sustancial, como el efecto de la destradicionalización de formas de vida producidas en la sociedad industrial. Destradicionalización que no debe ser entendida como la ausencia de tradiciones, sino como el cambio de estatus de la tradición en una sociedad: una en la cual las tradiciones estarían de forma constante y rutinaria sujetas a interrogación (Beck/Giddens/Lash 1997: 10). ¿Por qué este cuestionamiento? Porque, y es un punto central de su razonamiento, hemos entrado en una nueva fase de la modernidad -la segunda modernidad-, marcada por el hecho estructural que tenemos que enfrentar las consecuencias, por lo general no intencionales, producidas por la primera modernidad. Es en este sentido que la individualización se entiende como un proceso acompañante de la modernización reflexiva. Beck comprende este tipo de modernización como la auto confrontación con los resultados no deseados de la modernización industrial, que la precede, los que llevan, en última instancia, al quiebre de los fundamentos de este último tipo de sociedad, y por ende a un cuestionamiento sistemático de la tradición.

La individualización, sería, así, una consecuencia ambivalente de la ruptura del orden industrial, que abre una nueva forma de vincularse con lo social, la que puede entenderse a partir de tres dimensiones: dimensión de liberación (disolución de formas sociales precedentes), dimensión de desencanto (pérdida de seguridades tradicionales) y dimensión de control o de integración (nuevo tipo de cohesión social). (Beck 2006: 210). La individualización es inseparable de un diagnóstico de época. 


\section{Un nuevo individualismo institucional}

Este cambio de época (de naturaleza diacrónica) es particularmente visible en un corte sincrónico, dado el desarrollo que en la posguerra conoció el estado de bienestar. Sin detenerse nunca en exceso en las especificidades del estado de bienestar alemán con respecto a otras variantes nacionales (Esping-Andersen 1990), Beck subraya el aporte central de éste en tanto que orientación a gran escala hacia la individualización: la consolidación de un individualismo institucionalizado de nuevo cuño, uno en el cual, las instituciones mayores de la sociedad, en el marco de la segunda modernidad, se orientan de manera decisiva e inédita hacia el individuo.

Para Ulrich Beck, la individualización está, pues, ligada a la segunda modernidad y a la emergencia de lo que, retomando la expresión de Talcott Parsons, denomina un nuevo individualismo institucional. Las principales instituciones de la sociedad (el trabajo, el empleo, la escuela, la familia...) estarían cada vez más orientadas hacia el individuo, obligando a cada persona a desarrollar y asumir su propia trayectoria biográfica. Al calor de este nuevo individualismo institucional y de las prescripciones a las que se ve sometido, cada cual debe constituirse como individuo, dando forma a una sociedad de individuos. Como resultado, las formas tradicionales de vida y los contornos de los ambientes sociales se transforman (Beck/Beck-Gernsheim 2003).

Tal como lo ha subrayado Scott Lash (2003: 16), es posible leer que lo que Beck sostiene es que si antes las instituciones había que considerarlas como normas reguladoras, las actuales habría que entenderlas como normas constitutivas. Las instituciones antes que decirnos cómo hacer las cosas, expandirían solamente un mandato constitutivo al que debemos someternos: tomar la vida en nuestras propias manos. Hacernos cargo de las decisiones y las elecciones (que son por supuesto infinitamente menos libres de lo que se presentan) al mismo tiempo que de sus consecuencias. Como resultado de esta nueva constelación, entonces, los individuos deben enfrentar constantemente opciones y por lo tanto movilizar su capacidad de decisión.

En breve, el corazón de este segundo pilar de la tesis de la individualización puede enunciarse fácilmente: en la medida en que las instituciones no pueden ya transmitir de manera armoniosa las normas de acción, le corresponde a los individuos darle un sentido a sus trayectorias sociales por medio de la reflexividad (Giddens 1991; Beck/Beck-Gernsheim 2003; Bauman 2001).

\section{El sujeto reflexivo}

Beck reconoce que la individualización no podría ser considerada como una novedad contemporánea, y acepta, como diferentes autores han mostrado, que 
éste es un problema presente ya desde los clásicos de la sociología (Schroer 2000; Kalupner 2003; Kippele 1998; Junge 2002). No obstante, considera que la novedad consiste en que ahora, a causa de esta mutación institucional, es el individuo el que se convierte en "die lebensweltliche Reproduktionseinheit des Sozialen" (Beck 1986: 119), unidad de reproducción vital de lo social, idea ya contenida en el título de su temprano artículo "Jenseits von Stand und Klasse". En breve, la ruptura del orden industrial de la primera modernidad y el cambio operado a nivel de las instituciones, empuja a la aparición de un nuevo tipo de actor, un sujeto reflexivo en el doble sentido del término. Por un lado, un sujeto que se produce como reflejo de los cambios históricos que enfrenta . O sea, en un primer momento, Beck $(2006 ; 1986)$ entendió más el término en relación con la noción de reflejo y no como reflexión. Por el otro lado, progresivamente, y a veces incluso tan sólo de manera implícita, se desliza en sus trabajos la concepción de un sujeto reflexivo en el sentido de que sería capaz, gracias a sus competencias ordinarias y permanentes de análisis, evaluación y reflexividad, de enfrentar los fenómenos sociales.

Este sujeto reflexivo es, entonces, solicitado -y producido- de manera particular por un conjunto de instituciones sociales que lo obligan a desarrollar una biografía personal bajo la impronta de nuevas modalidades de prescripción normativa. Como lo resume Beck, los individuos deben dar soluciones biográficas a contradicciones sistémicas, que, en mucho, son el resultado imprevisto de la primera modernización (así lo testimonian, por ejemplo, los retos ecológicos inducidos por la industrialización específica a la primera modernidad (Beck/Giddens/Lash, 1997). En el marco de relaciones de desigualdad constantes, esta orientación hacia la individualización "liberó" a las personas de los vínculos de clase y los apoyos familiares, dejándolas, al mismo tiempo, cada vez más solas frente al mercado laboral, con sus riegos, contradicciones y oportunidades (Beck/Beck-Gernsheim 2003: 82 y ss.).

Para Beck, en la medida en que los enlazamientos vinculados con clase, familia y roles de género se debilitaron, el resultado no puede ser sino la aparición de crecientes procesos de reflexividad. Como efecto, retornó a los individuos el peso de la planificación biográfica, la organización de la vida y la gestión de la seguridad existencial, pasando de las biografías normales del modelo industrial de la primera modernidad, y a su tríada formación, actividad, jubilación, a las Bastelbiographien de la segunda modernidad. Ante la puesta en cuestión recurrente de la tradición y de las normas, serán los individuos los que deberán asumir las implicancias de "vivir su propia vida" (Beck 2001). Pero no sólo como una elección sino como un nuevo mandato institucional.

En breve, la sociedad industrial de la primera modernidad produjo estatus sociales asignados como la clase, el sexo, la nación. Con el tránsito a la segunda modernidad, estos intermediarios perdieron consistencia. Esto no implica- 
ría que los individuos sean más libres en sí mismos, sino que están sometidos a un nuevo proceso histórico que los produce a partir de nuevos factores -sobre todo desde otras prescripciones institucionalizadas-, y que demanda de ellos nuevas habilidades.

\section{Un potencial crítico}

Por último, para Beck, la indudable ganancia en libertad presente en este proceso de individualización va, sin embargo, acompañada de un aumento de los riesgos, de la precariedad, de la exclusión y sobrecarga del Individuo. Cierto, en última instancia, sigue considerándola una ganancia porque implica un aumento de la agencia, aumento que es producido por razones estructurales. Sin embargo, y es algo importante en su perspectiva y que lo diferencia sensiblemente, por ejemplo, de los trabajos más abiertamente optimistas de Giddens o de lecturas más unilateralmente pesimistas de la segunda modernidad, para Beck lo que prima es una ambivalencia: una lectura a la vez positiva y negativa de la individualización.

Este aspecto es importante. Aun cuando Beck se haya revelado relativamente insensible a las diversas modalidades de prescripción individualizadora propias a las diversas instituciones de la segunda modernidad, y aún más, que no haya subrayado con la fuerza debida los diferenciales que en términos de clase o de género poseen los individuos para construirse justamente como individuos, es a todas luces injusto minimizar su sensibilidad crítica. Beck es explícito al reformular el postulado sartriano: los individuos están condenados a la individualización. Una condena en la que los procesos de individualización están asociados, en forma inevitable, a nuevos mecanismos de dominación.

Si bien es cierto que Beck no ha prestado la atención que merece, a diferencia de muchos otros (Ehrenberg 1998; Bauman 2001; Castel/Haroche 2001; Martuccelli 2006), a la faz sombría de la individualización, sin embargo, su tesis nunca es unívoca. La individualización es un fenómeno irremediablemente ambivalente: o sea, en un mismo y solo movimiento, los individuos obtienen libertades y pierden seguridades. A cada cual, por supuesto, en función de su posición o trayectoria le cabe hacer su propio balance vital. No obstante, esto es secundario en última instancia: lo esencial es recordar que los individuos están condenados a enfrentar una experiencia que es constitutivamente ambivalente.

\section{Críticas e insuficiencias}

Antes de centrarnos en las maneras en que esta tesis ha sido recibida y recreada en la sociología chilena, vale la pena evocar algunas de las principales críti- 
cas a las que la tesis de la individualización ha sido sometida. Las críticas que se le han hecho a Beck son diversas: imprecisión histórica del diagnóstico de la segunda modernidad, híper-optimismo generalizado a pesar de la ambivalencia de la individualización, utilización metafórica de los términos. Las lecturas críticas no han subrayado solamente las dimensiones normativas presentes en la propuesta, sino que han interrogado, también, aspectos centrales de su diagnóstico, y, de manera importante, han dado lugar a líneas de investigación que intentaron probar la acuidad de la teoría contrastándola empíricamente. Para efectos de mis intereses argumentativos en este texto me detendré en tres de estas críticas: la puesta en cuestión de la caracterización de la época contemporánea como "Jenseits von Stand und Klassen” y, tras ello, sus limitaciones empíricas. Segundo, los impasses que devienen de la primacía unilateral de aspectos institucionales. Tercero, la vinculación, insuficientemente explicitada, entre individualización y autonomía. Cada uno de estos aspectos indicados por la crítica, ha tenido, como veremos, efectos importantes en su recepción en Chile.

La primera crítica, muchas veces con apoyo de investigación empírica, ha mostrado de qué manera los propios procesos de individualización siguen respondiendo, contrariamente a lo que afirma Beck en su diagnóstico de época, a criterios de clase. Scherr, por ejemplo, postula que los procesos de disolución de la familia o de los ambientes socio-morales, supuestos por Beck, no se han impuesto "sowie dass sich Individualisierungsprozesse keineswegs jenseits von Klasse und Stand sondern unter klassen-bzw schichtspezifischen Bedingungen vollziehen" (Scherr 2000: 193). ${ }^{4}$ Simonson ha mostrado, por su parte, que la falta de influencia de la pertenencia sociocultural -el estatus-, no aparece como un hecho claro: aunque puede confirmarse en ciertos ámbitos (aceptación institucional, por ejemplo), en otros (como la participación en organizaciones sociales) no es el caso (Simonson 2004). Estas críticas, de las que sólo mencionamos algunas aquí, no solamente acotan la pertinencia universal de la tesis propuesta por Beck, sino que, al someterla a contraste empírico, subrayan los límites y las formas distintas que este diagnóstico toma en función de las experiencias específicas según el contexto en el que se ubican los actores.

La segunda crítica tiene como blanco el privilegio que se le otorga a las dimensiones institucionales a la hora de caracterizar el proceso contemporáneo de individuación. A partir de esta perspectiva, la tesis tiene dificultades

4 "Tanto como que los procesos de individualización no se realizan más allá del estatus y la clase sino, por el contrario, bajo condiciones específicas de clase o sector socio económico" (traducción libre de la autora). 
para dar cuenta de muchos otros fenómenos estructurales que participan activamente en el proceso actual de fabricación de los individuos y que no pueden ser retrotraídos a consideraciones institucionales (Cf. Araujo y Martuccelli 2012). Por supuesto, las instituciones también participan en este proceso, pero lo hacen junto con otros factores sin duda más amplios, plurales y contradictorios. Por otro lado, al privilegiar la dimensión institucional pierde de vista que estos procesos de individuación no pueden estudiarse desde la sola óptica de la socialización (que, como sabemos, subyace en el modelo del individualismo institucional). Lo anterior debido a que en ellos participan factores que no son necesariamente internalizados por los actores y que, al ser descuidados, terminan haciendo del primado del individuo una manifestación ideológica que "oculta" otros fenómenos -como, por ejemplo, el rol específico del capital en su advenimiento (Žižek 2001).

La tercera crítica, tanto o más importante que las dos anteriores, se refiere a la vinculación directa que se establece entre individualización y autonomía. En rigor, la suposición de un aumento de autonomía como compañera inevitable de la individualización es un aspecto que Beck y Beck-Gernsheim han sido enfáticos en negar como una afirmación propia, más bien la han considerado explícitamente como una interpretación errada de sus intenciones. "Individualisierung (...) meint (...) nicht Atomisierung, nicht Vereinzelung, nicht Vereinsamung (...) auch nicht die albern schlichte Formel 'Individualisierung = Autonomie"“ (Beck/Beck-Gernsheim 1993: 2) $)^{5}$. No obstante, es evidente que en su obra hay más de un elemento que permite afirmar que esta asociación está implícita en el modelo de individuo que propone. La ambivalencia crítica de la tesis de la individualización cede por lo general delante el voluntarismo implícito presente en la figura del sujeto reflexivo, algo que se refleja en la mayor parte de las lecturas que se hacen de su obra, en las que se subraya, no sin razón, creemos, el empuje a la autonomía como parte constitutiva de su tesis (Volkmann 2007; Junge 2002). Volveremos sobre este punto más adelante.

\section{La tesis de la individualización en Chile}

¿Cómo ha sido recibida y recreada esta tesis en el marco de la sociedad chilena? Al evaluar la recepción de la tesis de la individualización en Chile se tiene que subrayar dos facetas. Por un lado, y es sin duda su aspecto más positivo, ella permitió incorporar el estudio sociológico del individuo. Colaboró, así,

5 "Individualización no significa atomización, atomización o aislamiento, como tampoco la simple y absurda fórmula individualización = autonomía" (traducción libre de la autora). 
tanto en la superación de enfoques casi exclusivamente centrados en el análisis de las estructuras sociales como en salir del marco restringido de la noción de identidad como instrumento de análisis. El individuo no fue un punto central de las preocupaciones de la región por largo tiempo. Por dos razones complementarias. Por un lado, porque en el pensamiento latinoamericano al contrario, fue más bien el tema de la ausencia de individuos o por lo menos su falencia lo que copó las discusiones y preocupaciones por décadas (Araujo 2009c; Martuccelli 2010). Si no había individuos, mal podíamos hacer nuestra esa parte de las preocupaciones de las ciencias sociales europeas. Por otro lado, y ahora desde el marco más restringido de la sociología, la recepción de la teoría de la modernización, el cepalismo y las teorías de la dependencia condujeron a privilegiar exclusivamente el interés por el análisis de las estructuras sociales (Vergara/Vergara 2002). El individuo no estaba considerado como una dimensión pertinente y de peso para tratar temas como el desarrollo o la modernización social. Desde esta perspectiva, vale la pena insistir en que la recepción de esta tesis tiene la función positiva de recuperar un ámbito de problemas que había quedado fuera (el individuo) y de aportar otros marcos interpretativos a la comprensión de la sociedad chilena más allá de lo estructural.

Por otro lado, no obstante, la recepción de esta tesis abrió a un conjunto de nudos problemáticos. Para mostrarlo, nos apoyaremos en cada uno de los cuatro puntos centrales de la tesis de la individualización.

\section{1. ¿Un diagnóstico de época? El peso de la historia nacional}

El enfoque de los procesos de individualización comienza a aparecer de manera importante en Chile en los noventa, en particular en la segunda parte de esta década. En efecto, a partir de esa fecha, una parte de los cientistas sociales comienzan a usar en Chile la clave de la individualización para comprender las transformaciones societales en el país. Según estos autores, también la sociedad chilena, como tantas otras sociedades actuales, viviría un proceso creciente de individualización como resultado de las transformaciones estructurales y culturales (Robles 2000; PNUD 2002; Díaz/Godoy/Stecher 2005; Herrera 2007; Guzmán/Godoy 2009; Soto 2009).

La recepción de la tesis se efectúa en un momento particular tanto desde un punto de vista social como intelectual. Por un lado, desde un punto de vista social e histórico, su recepción se realiza en íntima conexión con los procesos de modernización que se fueron profundizando en el país desde el cambio de rumbo político instaurado por la dictadura militar desde 1973 y la implementación del llamado modelo neoliberal. O sea, y es importante subrayarlo, es 
una experiencia interna de modernización, y de la inflexión que se observaba en ella en los años noventa a causa del retorno a la democracia y del nuevo rumbo impuesto por los primeros gobiernos de la Concertación (French Davies 2008), más que el fenómeno de la globalización lo que está en el telón de fondo de la recepción de la tesis en el país.

Son, por tanto, los efectos de la modernización neoliberal, los que producen los principales puntos de tensión teórica presentes en las ciencias sociales del país. Para unos, se habrían modificado los valores sociales con el aporte de los agentes del mercado (Moulian 1997) pero también como fruto de las disputas llevadas por los actores y los movimientos sociales (Garretón 2000). En este universo se habrían acelerado los ritmos vitales y se habrían, sobre todo, precarizado las relaciones laborales y sus regulaciones (Todaro/Yáñez 2004). Se habría asistido, por razones diversas, a un empuje en la transformación de las relaciones sociales, particularmente de género (Grupo Iniciativa Mujeres 2002), pero también entre las generaciones. Habrían surgido nuevas y más altas expectativas, con el inevitable acompañamiento de la frustración, al mismo tiempo que aumentó el nivel de vida de la población (Tironi et al. 2003). Se habría reestructurado, en el fondo, profundamente el paisaje de los soportes personales y colectivos con la aparición de una nueva familia de políticas sociales.

Frente al tenor de estos cambios, y en mucho como consecuencia de una toma de conciencia sólo parcial del agotamiento de antiguos paradigmas, las ciencias sociales chilenas fueron recorridas, en los años noventa, por un importante debate (Pinedo 1997). Éste se centró tanto en la naturaleza específica de la modernidad y de la modernización en Chile como en una evaluación normativa de los éxitos o fracasos obtenidos luego de varias décadas de desarrollo bajo la égida del modelo neoliberal. Un debate dentro del cual vino a terciar la tesis de la individualización. Pero, entre muchos de los partidarios de esta tesis, no todos, es justo subrayar, es visible a este nivel la escasa atención que muestran sino necesariamente hacia los rasgos propios de la sociedad chilena, por lo menos hacia las especificidades del proceso de modernización desde el cual Beck formuló su diagnóstico de época.

Al admitir el proceso histórico de la individualización producido para el caso alemán como un modelo para interpretar los datos de otras sociedades, se corrió el riesgo de velar las especificidades de los procesos de individuación en esas otras sociedades. Al hacer uso de una lectura histórica como un modelo teórico aplicable a otras realidades, el precio a pagar fue que se velaron las verdaderas especificidades de la individuación en el caso chileno y que se reintrodujo con fuerza, como veremos en un momento, la figura del individuo por déficit, un viejo conocido en los esfuerzos de la región por pensarse a sí misma. 


\section{2. ¿Un individualismo institucional? Individuos sin asistencia}

La segunda consideración crítica es aún más decisiva. Pocas cosas resultan menos pertinentes para estudiar las experiencias individuales en América Latina, incluso en el caso de una sociedad como la chilena, que es sin duda una de las más institucionalizadas de la región, que privilegiar el trabajo de las instituciones. Como los resultados de una investigación reciente muestran ${ }^{6}$, solo al costo de ciertas amputaciones el individuo en Chile puede ser aprehendido desde una variante del individualismo institucional. ${ }^{7}$

En Chile, la situación ha sido y es distinta. No solamente el imperio de las normas es problemático (Araujo 2009b), sino que a causa de particularidades estructurales, un conjunto significativo de iniciativas individuales tienden a afirmarse por fuera o en contra de las instituciones. En un solo y mismo movimiento, los cambios de la vida social son percibidos como generando expectativas que las instituciones no logran estructuralmente canalizar (Araujo 2009a).

Esta tensión entre expectativas e iniciativas es una experiencia particularmente significativa en un país como Chile, en donde a causa del conjunto de importantes transformaciones ocurridas en las últimas décadas (consumo, escolarización, urbanización, extensión de los derechos ciudadanos...), muchos individuos se sienten por "delante" de sus instituciones.. La dialéctica entre las instituciones y los actores no se produce sino de manera transitoria y puntual, bajo la figura del acuerdo.. No se trata solamente que los actores, en ciertos casos y dentro de ciertos límites, "colmen" las brechas de las instituciones, sino que de manera estructural el individuo tiene que construirse teniendo en cuenta las falencias -y las oportunidades relativas- de éstas). El actor a la vez que "depende" de las instituciones, se concibe a "distancia" de ellas. Incluso más, con mucha frecuencia debe defenderse de ellas. Por eso, no cesa de sentirse conminado a un desafío mayor: saberse -sentirse- en el fondo

${ }^{6}$ Las reflexiones presentadas en este apartado provienen de los resultados de la investigación "Procesos de individuación y configuración de sujeto en la sociedad chilena actual", de la que fui investigadora responsable entre 2008 y 2011. El estudio fue desarrollado en colaboración con Danilo Martuccelli, y contempló la realización de alrededor de cien entrevistas en profundidad a hombres y mujeres entre 30 y 55 años de los sectores de menores recursos y medios altos. Sus resultados han sido presentados en Araujo y Martuccelli 2012.

${ }^{7}$ La noción de institución es polisémica y algunos autores dan una caracterización tan amplia de ella que todo fenómeno social que se reproduce se convierte en una institución. Por eso resulta aconsejable movilizar una concepción más restringida y precisa del término: definir como institución a un número reducido de principios legítimos encarnados en organizaciones sociales específicas. Las instituciones se entienden así tanto en el sentido de un conjunto de normas que son interiorizadas y respetadas, como de un conjunto de anhelos que, al ser legítimos y regulados, intentan ser obtenidos por los actores. 
solo. Pero una soledad que no es de índole existencial, sino que es el fruto de una experiencia plenamente social.

Este sentimiento de solipsismo condensa uno de las grandes especificidades de los individuos en Chile. A saber, que los individuos se forjan enfrentando instituciones que generan insumos ambivalentes y que, por lo general, los defienden insuficientemente. Los actores tienen que protegerse a veces de sus abusos; otras, de la severidad e inadecuación de sus prescripciones. En los dos casos, lo que prima, muchas veces sin duda de manera excesiva, es el sentimiento de que "el" colectivo político se desresponsabiliza de la suerte personal de cada uno de ellos. Es en este sentido como debe comprenderse que el modo de individuación propio a la sociedad chilena no es, en su centro, un individualismo institucional. Su individualización no es el fruto de un trabajo institucional. Ésta es una realidad que cuestiona radicalmente -o sea, desde su raíz- la pertinencia de la tesis de la individualización.

El proceso de individuación forja, de este modo, individuos que tienen que asegurar su continuidad en la vida social desde ellos mismos. Los individuos son actores en el sentido más fuerte del término: deben constantemente hacer frente a imprevistos tanto a nivel macro (inflaciones, inestabilidades políticas, choques de eventos externos...) como micro (despidos, evoluciones familiares, problemas de salud...). Una situación que produce socialmente un individuo que tiene que hacerse cargo de sí mismo de una manera particular. Por supuesto, como en todos lados es responsable de su vida y, también, como en todos lados, para lograrlo, moviliza un conjunto de recursos diversos. Se ve obligado a utilizar estrategias altamente individualizadas debido a que se encuentran marcadas por el sello de una contingencia relacional permanente. Cierto, estos recursos se apoyan sobre costumbres (pensemos la lógica del de las influencias personales o las redes), pero éstas no pueden ser consideradas como verdaderas inscripciones institucionales.

En Chile, y en el marco de la tesis de la individualización, Robles (2000: capítulo 2) ha subrayado esta especificidad. Los individuos enfrentan solos, en todo caso más solos que en otros lares, el proceso de individuación, puesto que se ven obligados a buscar respuestas por sí mismos a una serie de falencias, como las del mercado de trabajo formal, por ejemplo, lo que los obliga a hacer del trabajo temporal o estacional, de la subcontratación, del trabajo a domicilio o clandestino, una forma forzosa de subsistencia. Si en los países del Norte habría, entonces, una auto-confrontación asistida (por las instituciones), en un país como Chile habría una auto-confrontación desregulada que incrementa las inseguridades ontológicas. ${ }^{8}$ Es esto lo que los obliga a tejer y sostener

${ }^{8}$ Señalemos para evitar todo malentendido que en este artículo movilizamos las nociones de individuación e individualización de manera distinta a como lo propone el autor, que 
redes. Es decir, el apoyo no se encuentra principalmente en las instituciones, sino que tiene que ser producido (o al menos sostenido) por el mismo individuo por medio de redes de favores y reciprocidades que el autor denomina como un "sistema funcional alternativo". Y esto, muchas veces, en medio de situaciones de exclusión, lo cual supone una modalidad específica de sujeto.

\section{3. ¿El sujeto reflexivo? Un horizonte normativo problemático}

Como ya señalamos, los autores que recogen la tesis de la individualización introducen una perspectiva relevante en los estudios sociales chilenos: el interés por el problema del individuo y de los procesos de individuación. Sin embargo, y a pesar de lo anterior, la recepción de la tesis de la individualización en el caso chileno va a darse, involuntariamente y de modo sinuoso, en el marco de la tradición de lo que podríamos llamar una lectura deficitaria del individuo en América Latina (Araujo 2009c y 2009d; Martuccelli 2010). Es decir, una lectura caracterizada por la idea ampliamente aceptada de que, en estas latitudes, el individuo en el sentido moderno noroccidental era, y es, ante todo un "proyecto". Esta concepción está íntimamente vinculada con las discusiones sobre la modernidad latinoamericana, una discusión en la que con frecuencia se construyó una perspectiva analítica que ponía el énfasis en la distancia entre nuestras realidades y el modelo noroccidental y los supuestos normativos que lo acompañaban, entre ellos, por cierto, la noción de individuo (García Canclini 1999 y 1995; Martín-Barbero 2001 y 1989; Cornejo Polar 1994; Sarlo 1988). Lo que se subraya aquí es pues la brecha constante que existe entre la realidad social de América Latina y el modelo noroccidental, asociada a la aspiración de remontar esta distancia. En esta perspectiva, el individuo se constituye en un proyecto inconcluso pero en marcha.

Es esta misma antigua perspectiva la que se infiltra en los diferentes enfoques y estudios que se hicieron desde la óptica de la individualización. La tesis funciona siempre asociada a un horizonte normativo, aunque en algunos sea utópico, como en el caso de los estudios de género y feministas o de los Informes de Desarrollo Humano del PNUD, y en otros no, como por ejemplo en el trabajo comparativo de Herrera (2007). Pero en todos los casos, se evalúan las situaciones a partir del tipo de individuo que supone este horizonte normativo.

tiende a asociar la individualización con una faz luminosa y la segunda, la individuación, con procesos esencialmente negativos. Regresaremos sobre este punto, pero esta distinción, amén que se condice con la manera como habitualmente se usan estos términos, señala la insuficiencia de la sociología chilena para comprender la ambivalencia intrínseca activa en el proceso de fabricación de los individuos. 
Ahora bien, los horizontes normativos presentes en la tesis de la individualización tienen, como lo hemos indicado en nuestra lectura de la obra de Beck, como implícito un modelo de individuo no solamente estrechamente vinculado a la tradición noroccidental, sino que privilegia una versión particular de esta tradición. En efecto, la individualización trabaja dentro de un horizonte normativo específico que supone un individuo que tiene como rasgos constitutivos centrales los ideales de autonomía, autodeterminación y reflexividad. La inscripción de la tesis de la individualización dentro de esta tradición enmarca y explica su recepción en América Latina, puesto que en esta región, por razones de contingencia histórica, este modelo de individuo ha sido siempre el teatro de un traslape conceptual a través del cual, sistemáticamente, la noción de individuo filosófico abstracto de la ciudadanía se imponía siempre a la noción sociológica del individuo concreto (Araujo 2009c).

Nada testimonia mejor de este lazo que el hecho que son precisamente estos rasgos (el modelo del ciudadano y del individuo abstracto), los que en la recepción que se hace de la tesis de la individualización en el caso chileno funcionarán como los indicadores centrales del nivel de la individualización observable en el país. En todo caso, fue por la asociación entre modelo de individuo y horizonte normativo como el problema de la individualización fue movilizado para abordar el tema más general de las metas de la democratización vía la ciudadanización de los diferentes sectores de la sociedad. Una asociación particularmente visible en los aportes de los estudios de género y feministas.

No se trata de un ejemplo entre otros: es posible sostener que uno de los ámbitos de recepción más extendido y fecundo dentro de las ciencias sociales chilenas de la tesis de la individualización son los estudios de género y feministas (y las nuevas interrogaciones que florecieron vinculadas al ámbito de la intimidad, la privacidad o la sexualidad). Si bien estos estudios se desarrollan en algunos casos desde el marco de las subjetividades e identidades, lo que es importante es que ellos tienen como motor implícito la pregunta por el individuo y su constitución. ¿Por qué? Porque estos estudios están enmarcados en un horizonte normativo: la producción de las mujeres como individuos (Araujo 2009c).

Esto es particularmente fuerte en el llamado feminismo de la igualdad. En éste la meta de emancipación de las mujeres pasa por la constitución de las mismas como individuos, no sólo en sentido de ser reconocidas como tales (ciudadanía), sino por la adquisición de ciertos rasgos en cada caso individual. De esta manera, la autonomía, autodeterminación y reflexividad son elementos centrales de las apuestas políticas de esta posición: por un lado, en el papel otorgado al individuo y su transformación; por el otro, en la politización de lo privado y de la intimidad como núcleo de nuevas propuestas de comprensión e 
intervención en lo social. En este marco, resulta fácil comprender el por qué de la recepción -relativamente acrítica- de la tesis de la individualización. Ella daba un marco que permitía asociar el horizonte normativo a un proceso histórico y a una propuesta teórica, y al mismo tiempo asociarla con los objetivos de democratización social (democratización de las relaciones entre los géneros).

Pero al hacerlo, al adherir y por ende imponer definiciones normativas histórica y culturalmente determinadas para otras realidades, esta recepción no pudo en los hechos sino preservar, bajo nuevas coordenadas, la sempiterna lectura deficitaria del individuo en la región. Los actores son siempre percibidos como insuficientemente reflexivos y autónomos.

\section{4. ¿Un potencial crítico? Un optimismo unilateral}

En cuarto lugar, la recepción de la tesis de la individualización, al ser hecha en el contexto de un crecimiento económico sostenido y de mejora indudable del nivel de vida en Chile, y concebida como fundamento para alcanzar el horizonte de democratización de la sociedad que impera como ideal y promesa social, tenderá (aunque ciertamente no en todos los casos) a recoger los aspectos más positivos y optimistas de la misma. La individualización será leída prioritariamente como una oportunidad y una ampliación de las libertades y de la agencia. Más que como la compañera de la incertidumbre social, la individualización será vista como modelo para la agencia en contextos ya sea de transformación social, como en el caso de las relaciones de género que ofrecen a las mujeres nuevas oportunidades y espacios que deben poder ocupar (Valdés/Valdés 2005; Mauro/Godoy 2001; Guzmán/Godoy 2009) de precarización y fragilización de lazos, como en las discusiones sobre los nuevos malestares culturales (PNUD 1998, 2000, 2002, 2009); de nuevos sentidos subjetivos suscitados por las estrategias en el mercado de trabajo (Díaz/Godoy/Stecher 2005) o frente a la pobreza (Robles 2000). En todos los casos, incluso cuando se reconocen dificultades o escollos, la individualización aparece como una meta deseable, positiva y en curso.

Este punto es particularmente transparente en los Informes de Desarrollo Humano del PNUD. Realizado por un equipo de cientistas sociales en el marco institucional del sistema de Naciones Unidas, estos informes se proponen como instrumento sociológico para la apertura de debate político. Aunque no desde sus inicios, en 1998, el Informe adquirió a partir notoriamente del año 2000, el enfoque de la individualización. En la definición de los procesos de individualización se pone el acento en "la capacidad de los individuos para definir por su cuenta y riesgo lo que quieren ser" (PNUD 2002: 20), capacidad 
de decisión, ruptura de lazos tradicionales, mayor capacidad de autorrealización. La individualización, asociada a los horizontes normativos del Informe, es, así, considerada como una vía inequívoca de emancipación: "El chileno tiende a romper los vínculos sociales y los hábitos tradicionales que, a la vez, lo encerraban y lo protegían. Esta 'salida al mundo' forma parte de un proceso de emancipación que permite al individuo ampliar su horizonte de experiencias, incrementar su capacidad de participación en la vida social y desarrollar su opción de autorrealización" (PNUD 2002: 89). Aunque los autores consideran y discuten los riesgos de la individualización, el informe adhiere, en su esqueleto normativo, al lado positivo de la misma. Para decirlo más claramente: la individualización es un horizonte de emancipación, que, ciertamente, y en función de ciertos contextos o escasez de recursos, puede presentar ciertas facetas negativas.

Como se puede apreciar, si en la versión alemana de esta tesis, una de las críticas principales que se le hizo (y ello a pesar del reconocimiento explícito que Beck hace de la ambivalencia de este proceso) fue el haber subrayado en exceso el peso de la autonomía, lo que supone atribuirle a los individuos por ende espacios demasiado optimistas de libertad y agencia, es precisamente esta deriva lo que hará atractiva la tesis en el caso chileno.

Si la individualización en el caso alemán está pues más cercana al tema de la recomposición del vínculo social y a los riesgos que se produce por su debilitamiento (lo que incluye por ende indisociablemente una faz negativa en este proceso), en el caso chileno, la individualización es un horizonte normativo sin tachas para la construcción de vínculos más democráticos. El individuo de la individualización aparece, así, como promesa del sostén necesario para la consolidación democrática.

Al subrayarse en la recepción una lectura positiva de la individualización, se oblitera o se deja sin discutir una dimensión que Beck mismo (así como otros autores) se han encargado de reiterar: a saber, que estos procesos de individualización están asociados a nuevos mecanismos de dominación. Los índices positivos que pueden ser exhibidos tienen que tomar en cuenta, al mismo tiempo, sus efectos negativos cuando recaen en las espaldas de individuos ubicados en situaciones de vulnerabilidad permanente, sometidos a sobrecargas laborales y financieras diversas. Una ambivalencia no suficientemente presente en los trabajos sobre la individualización en Chile.

\section{Renovar los estudios sobre la individuación}

¿Qué consecuencia extraer de estos impasses? Para empezar, que una mirada crítica a la tesis de la individualización no puede de ninguna manera traducirse 
en un abandono del interés por el proceso de individuación. Por el contrario. Primero porque esta perspectiva de estudio, aparece como cada vez más idónea en el marco de sociedades diferenciadas y complejas, en las cuales la confianza en lecturas que otorgan todo el papel heurístico a la dimensión estructural aparece cada vez más como problemática. Pero, también, porque en nuestras sociedades se afirma una sensibilidad social particular, que exige dar cuenta a escala de los actores de los problemas sociales. Se trata de una doble realidad que aconseja pasar por el individuo para llegar a la comprensión de la sociedad. Una perspectiva que no hace sino recoger la intuición señalada tempranamente por Norbert Elias: en sociedades altamente complejas y diferenciadas, son los individuos los que están en la mejor posición para dar cuenta de las exigencias, tensiones y contradicciones en juego en una sociedad (Elias 1990). Pero, de otro lado, es necesario cuidar que la aplicación de esta perspectiva de estudio no traicione la especificidad de las realidades sociales particulares. Para ello parece aconsejable introducir tres grandes inflexiones (Araujo/Martuccelli 2010).

En primer lugar, se precisa realizar un diagnóstico más preciso de nuestra época, lo que requiere, a diferencia de lo que afirman los teóricos de la segunda modernidad y aún más los trabajos últimos de Beck sobre el cosmopolitismo, subrayar las variantes nacionales en las que se dan -se siguen dando- los procesos de individuación. Las experiencias de los individuos, cualquiera que sea la realidad parcial de lo global, siguen siendo hoy profundamente nacionales. Y lo son en un país como Chile.

En segundo lugar, se requiere dar cuenta, sobre nuevas bases, de la articulación entre los fenómenos estructurales y las experiencias subjetivas. Para ello, es preciso evitar los excesos y los déficits asociados a un enfoque centrado en los procesos de socialización. Los excesos: los trabajos que continúan afirmando un vínculo único entre un tipo de sociedad y un tipo de personalidad (de Riesman 1981 a Lasch 1999). Los déficits: los trabajos que sólo logran dar cuenta de la pluralidad de los individuos desde sus procesos disímiles y contradictorios de socialización (Lahire 2004; Kaufmann 2001). La renovación de los operadores analíticos tendrían que conducirnos a ser más sensibles no solamente respecto a las variaciones existentes en los distintos ámbitos sociales (lo que se produce en el ámbito laboral, por ejemplo, no es isomorfo a lo que acaece en la escuela o en la familia), sino también a las diferentes vías de individuación observables en función de las posiciones sociales, géneros o edad. Cuestiones analíticas que la noción de prueba, como nos lo deja entrever ciertos trabajos, y en particular una investigación sobre el proceso de individuación en la sociedad chilena actual, permite afrontar con éxito (Martuccelli 2006; Araujo/Martuccelli 2010; Araujo/Martuccelli 2012).

En tercer lugar, resulta necesario que la sociología tome en cuenta, de manera más activa a como lo ha hecho en el pasado, el trabajo de los indivi- 
duos para producirse como sujetos. En este punto la dificultad de la tesis de la individualización es evidente. Si bien, una de las principales consecuencias del proceso descrito por Beck es que los cambios sociales son más visibles desde las biografías personales que desde los grupos o las clases sociales, paradójicamente la tesis de la individualización propone un paisaje extremadamente homogéneo de los procesos contemporáneos. Se pierde así de vista la multiplicidad de modos en que el individuo se puede producir o el sujeto se puede configurar (Araujo 2009a y 2009d). Para subsanar esta carencia es preciso abrir la sociología de la individuación hacia el trabajo de los individuos: o sea, una interrogación por el trabajo específico que el actor efectúa en el curso del proceso de individuación para configurarse como sujeto. Algo que impone la necesidad de romper con la tendencia, tan frecuente en los análisis sociológicos, de dejar fuera del estudio el problema del sujeto en el sentido preciso del término.

Vale la pena insistir: frente a las aristas problemáticas de la tesis de la individualización, tanto en Alemania como en su recepción en Chile, aquí abordadas, e incluso por razones disímiles, la sociología no debe abandonar su interés por el individuo, sino que requiere renovarlo. Más que nunca se impone la necesidad de abordar el estudio de las sociedades partiendo de los individuos, pero, nos parece, poniendo de manera simultánea el acento en los procesos estructurales de individuación y en el trabajo de los individuos. Se trata de una conversación en dos niveles autónomos pero dialogantes: "hacia arriba": poner en relación el individuo con el registro social -y permitir aislar el conjunto estandarizado de desafíos específicos a una sociedad. "Hacia abajo": abrir al estudio efectivo por el cual el individuo se constituye como sujeto -lo que exige una lectura de este trabajo considerándolo siempre historizado de forma peculiar. Lo que se requiere es, así, hacer de la individuación el verdadero eje central de la sociología, y describir en el marco de ella, los procesos personalizados de producción de los individuos en sujetos.

\section{Bibliografía}

Araujo, Kathya (2009a): Habitar lo social. Santiago de Chile: LOM Ediciones.

- (2009b): ¿Se acata pero no se cumple? Santiago de Chile: LOM Ediciones.

- (2009c): "Individuo y Feminismo. Notas desde América Latina", en: Iconos, n 33 , pp. 141-153.

- (2009d): Dignos de su arte. Sujeto y lazo social en el Perú de las primeras décadas del siglo XX. Madrid/Frankfurt: Iberoamericana/Vervuert.

Araujo, Kathya/Martuccelli, Danilo (2010): "La individuación y el trabajo de los individuos", en: Educaçao e Pesquisa, vol. 36, pp. 77-91. 
- (2012): Desafios Comunes. Retrato de la sociedad chilena y sus individuos. Santiago: LOM.

Bauman, Zygmunt (2001): La sociedad individualizada. Madrid: Cátedra.

BECK, Ulrich (1984): "Jenseits von Stand und Klasse. Auf dem Weg in die individualisierte Arbeitsnehmergesselschaft", en: Merkur, vol. 38, no 5, pp. 485-497.

- (1986): Risikogesellschaft. Auf dem Weg in eine andere Moderne. Frankfurt: Suhrkamp.

- (1997): "La reinvención de la política: hacia una teoría de la modernización reflexiva”, en: Beck, Ulrich/ Giddens, Anthony/Lash, Scott: Modernización reflexiva. Política, tradición y estética en el orden social moderno. Madrid: Alianza, pp. 13-73.

- (2001): "Vivir nuestra propia vida en un mundo desbocado: individualización, globalización y política", en: Hutton, Will/Giddens, Anthony (eds.): En el límite: la vida en el capitalismo global. Barcelona: Tusquets.

- (2006): La sociedad del riesgo. Barcelona: Paidós.

BECK, Ulrich/BECK-GERNSHEIM, Elisabeth (1993): "Nicht Autonomie sondern Bastelbiographie", en: Zeitschrift für Soziologie, no 22, pp. 178-187.

- (2003): La individualización. El individualismo institucionalizado y sus consecuencias sociales y políticas. Barcelona: Paidós.

Beck, Ulrich/Giddens, Anthony/Lash, Scott (1997): Modernización reflexiva. Politica, tradición y estética en el orden social moderno. Madrid: Alianza.

Castel, Robert/Haroche, Claudine (2001): Propriété privée, propriétés sociale, propriété de soi. Paris: Fayard.

Cornejo Polar, Antonio (1994): Escribir en el aire. Lima: Editorial Horizonte.

Díaz, Ximena/Godoy, Lorena/STecher, Antonio (2005): Significados del trabajo, identidad y ciudadanía. La experiencia de hombres y mujeres en un mercado laboral flexible. Santiago de Chile: Cuaderno de investigación n ${ }^{\circ} 3, \mathrm{CEM}$.

EHrenBerg, Alain (1998): La fatigue d'être soi. Paris, Odile Jacob.

EliAs, Norbert (1990): La sociedad de los individuos. Barcelona: Península.

EsPInG-ANDERsEn, Gösta (1990): The Three Worlds of Welfare Capitalism. Cambridge: Polity Press.

FRENCH DAVIS, Ricardo (2008): Chile entre el neoliberalismo y el crecimiento con equidad. Santiago de Chile: J. C. Sáez Editor.

García Canclini, Néstor (1995): Consumidores y ciudadanos. México: Grijalbo.

- (1999): La globalización imaginada. Barcelona: Paidós.

Garretón, Manuel-Antonio (2000): La sociedad en qué vivi(re)mos. Santiago de Chile: LOM Ediciones.

Giddens, Anthony (1991): Modernity and Self-Identity. Cambridge: Polity Press.

- (2003): Consecuencias de la modernidad. Madrid: Alianza.

GuZMÁN, Virginia/Godoy, Lorena (2009): "Individuación y normatividad de género: la construcción de proyectos biográficos de mujeres”, en: Araujo, Kathya (ed.): ¿Se acata pero no se cumple? Santiago de Chile: LOM Ediciones, pp. 175-197.

Herrera Ponce, María Soledad (2007): Individualización social y cambios demográficos. Madrid: CIS/Siglo XXI.

Junge, Matthias (2002): Individualisierung. Frankfurt: Campus Verlag. 
KaluPNer, Sybille (2003): Die Grenzen der Individualisierung. Handlungstheoretische Grundalgen einer Zeitdiagnose. Frankfurt: Campus.

Kaufmann, Jean-Claude (2001): Ego. Paris: Nathan.

KIPPELE, Flavia (1998): Was heisst Individualisierung? Die Antworten Soziologischer Klassiker. Opladen/Wiesbaden: Westdeutscher Verlag.

LAHIRE, Bernard (2004): El hombre plural. Los resortes de la acción, Barcelona: Ediciones Bellaterra.

LASCH, Christopher (1999): La cultura del narcisismo. Santiago de Chile: Andrés Bello.

LASH, Scott (2003): "Individualización a la manera no lineal“, en: Beck, Ulrich/BeckGernsheim, Elisabeth (eds.): La Individualización. Barcelona: Paidós.

GRUPO INICIATIVA MuJERES (2002): El nuevo contrato social: balance de una década de democracia en Chile. Santiago de Chile: Grupo de Iniciativa Mujeres.

Martín-Barbero, Jesús (1989): Procesos de comunicación y matrices de cultura. México: G. Gili.

- (2001): Al sur de la modernidad. Comunicación, globalización y multiculturalidad. Pittsburgh: Instituto Internacional de Literatura Latinoamericana.

MartucCelli, Danilo (2006): Forgé par l'épreuve. Paris: Armand Colin.

- (2010): ¿Existen individuos en el Sur? Santiago de Chile: LOM Ediciones.

MartucCelli, Danilo/Singly, François de (2009): Les sociologies de l'individu. Paris: Armand Colin.

MaUro, Amalia/Godoy, Lorena (2001): "Las relaciones de pareja y los cambios en el mercado de trabajo: el punto de vista de los hombres", en: Revista de la Academia, $\mathrm{n}^{\mathrm{o}} 6$, pp. 129-147.

Moulian, Tomás (1997): Chile actual: anatomía de un mito. Santiago de Chile: LOM Ediciones.

PINEDO, Javier (1997): "Chile a fines del siglo Xx: entre la modernidad, la modernización, la identidad”, en: Universum, $\mathrm{n}^{\mathrm{0}} 12$, pp. 141-180.

PNUD, Informe SOBRE El Desarrollo Humano (1998): Las paradojas de la modernización. Santiago de Chile: PNUD.

- (2000): Más sociedad para gobernar el futuro. Santiago de Chile: PNUD.

- (2002): Nosotros los chilenos: un desafio cultural. Santiago de Chile: PNUD.

- (2009): La manera de hacer las cosas. Santiago de Chile: PNUD.

RIESMAN, David et al. (1981): La muchedumbre solitaria. Barcelona: Paidós.

Robles, Fernando (2000): El desaliento inesperado de la modernidad. Santiago de Chile: RIL Editores.

SARLO, Beatriz (1988): Una modernidad periférica: Buenos Aires 1920 y 1930. Buenos Aires: Nueva Visión.

SCHERR, Albert (2000): "Individualisierung - Moderne - Postmoderne. Eine Auseinandersetzung mit dem Individualisierungstheorem in der Perspektive eines kritischen Postmodernismus", en: Kron, Thomas (ed.): Individualisierung und soziologische Theorie. Opladen: Leske und Budrich, pp. 185-202.

Schimank, Uwe/Volkmann, Ute (eds.) (2007): 2. Auflage Soziologische Gegenwarsdiagnosen I. Eine Bestandaufnahme. Wiesbaden: VS Verlag für Sozialwissenschaften. 
SCHROER, Markus (2000): Das Individuum der Gesellschaft. Frankfurt: Suhrkamp.

SimONSON, Julia (2004): Individualisierung und soziale Integration. Zur Entwicklung der Sozialstruktur und ihrer Integrationsleistungen. Wiesbaden: Deutscher Universitäts- Verlag.

Sото, Álvaro (2009): "Formas y tensiones de los procesos de individualización en el mundo del trabajo", en: Psicoperspectivas, vol. VIII, no 2, pp. 102-119.

Tironi, Eugenio et al. (2003): Cuánto y cómo cambiamos los chilenos. Balance de una década. Santiago de Chile: INE.

Todaro, Rosalba/YÁñEz, Sonia (eds.) (2004): El trabajo se transforma. Santiago de Chile: CEM.

VAldÉs, Ximena/VAldÉs, Teresa (eds.) (2005): Familia y vida privada. ¿Transformaciones, tensiones, resistencias o nuevos sentidos? Santiago de Chile: CEDEM/ UNFPA/Flacso-Chile.

VERGARA, Jorge/VERGARA, Iván (2002): "Cuatro tesis sobre la identidad cultural latinoamericana. Una reflexión sociológica”, en: Revista de Ciencias Sociales, n 12, pp. 81-96.

Volkmann, Ute (2007): "Das schwierige Leben in der Zweiten Moderne - Ulrich Becks 'Riskogesselschaft'”, en: Schimank, Uwe/Volkmann, Ute (eds.): 2. Auflage Soziologische Gegenwartsdiagnosen I. Eine Bestandaufnahme. Wiesbaden: VS Verlag für Sozialwissenschaften, pp. 23-40.

ŽIŽEK, Slavoj (2001): El espinoso sujeto. Barcelona: Paidós. 